\title{
SEOM Clinical Guideline in ovarian cancer (2016)
}

\author{
A. Santaballa ${ }^{1}$ P. Barretina ${ }^{2} \cdot$ A. Casado ${ }^{3}$ - Y. García ${ }^{4}$ - A. González-Martín ${ }^{5}$.

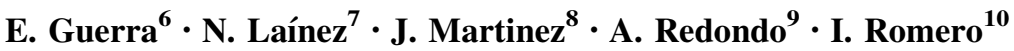

Received: 17 November 2016/Accepted: 17 November 2016/Published online: 30 November 2016

(C) The Author(s) 2016. This article is published with open access at Springerlink.com

\begin{abstract}
Despite remarkable advances in the knowledge of molecular biology and treatment, ovarian cancer (OC) is the first cause of death due to gynecological cancer and the fifth cause of death for cancer in women in Spain. The aim of this guideline is to summarize the current evidence and to give evidence-based recommendations for clinical practice.
\end{abstract}

Keywords Ovarian cancer · Treatment guidelines · First line $\cdot$ Recurrent disease

A. Santaballa

santaballa_ana@gva.es

P. Barretina

mpbarretina@iconcologia.net

A. Casado

antoniocasado6@gmail.com

Y. García

ygarcia@tauli.cat

A. González-Martín

agonzalezm@seom.org

E. Guerra

eva_m_guerra@hotmail.com

N. Laínez

nuria.lainez.milagro@cfnavarra.es

J. Martinez

jeronimo@seom.org

A. Redondo

aredondo12@gmail.com

I. Romero

iromero@fivo.org

1 Servicio de Oncología Médica, Hospital Universitari I Politècnic La Fe, Avda de Fernando Abril Martorell, n. 106, 46026 Valencia, Spain

\section{Introduction}

Despite continuous advances in hereditary ovarian cancer (OC) identification to prevent it, surgical efforts in the upper abdomen, new insights in molecular heterogeneity, and new therapies, OC remains the most lethal gynecological cancer [1]. Most patients will present with advanced FIGO stage III or IV disease and around two-thirds will ultimately relapse. In this scenario, the increase in quality of life and survival is based on a multidisciplinary

2 Servicio de Oncología Médica, Institut Català d'Oncologia, Girona, Spain

3 Servicio de Oncología Médica, Hospital Clínico Universitario, San Carlos, Madrid, Spain

4 Servicio de Oncología Médica, Corporació Sanitària Parc Taulí, Sabadell, Spain

5 Servicio de Oncología Médica, MD Anderson Cancer Center, Madrid, Spain

6 Servicio de Oncología Médica, Hospital Universitario Ramón y Cajal, Madrid, Spain

7 Servicio de Oncología Médica, Complejo Hospitalario de Navarra, Pamplona, Spain

8 Servicio de Oncología Médica, Hospital Universitario Virgen de la Arrixaca, Murcia, Spain

9 Servicio de Oncología Médica, Hospital Universitario La Paz, Madrid, Spain

10 Servicio de Oncología Médica, Fundación Insituto Valenciano de Oncología, Valencia, Spain 
approach. The aim of this guideline is to summarize the current evidence and to give evidence-based recommendations for clinical practice.

\section{Methodology}

SEOM guidelines have been developed with the consensus of ten OC oncologists from the cooperative groups GEICO and SEOM. To assign a level and quality of evidence and a grade of recommendation to the different statements of this treatment guideline, the Infectious Diseases Society of America-US Public Health Service Grading System for

Table 1 Strength of recommendation and quality of evidence score

\begin{tabular}{|c|c|}
\hline Category, grade & Definition \\
\hline \multicolumn{2}{|l|}{$\begin{array}{l}\text { Strength of } \\
\text { recommendation }\end{array}$} \\
\hline A & $\begin{array}{l}\text { Good evidence to support a recommendation } \\
\text { for use }\end{array}$ \\
\hline B & $\begin{array}{l}\text { Moderate evidence to support a } \\
\text { recommendation for use }\end{array}$ \\
\hline $\mathrm{C}$ & Poor evidence to support a recommendation \\
\hline $\mathrm{D}$ & $\begin{array}{l}\text { Moderate evidence to support a } \\
\text { recommendation against use }\end{array}$ \\
\hline $\mathrm{E}$ & $\begin{array}{l}\text { Good evidence to support a recommendation } \\
\text { against use }\end{array}$ \\
\hline \multicolumn{2}{|c|}{ Quality of evidence } \\
\hline I & $\begin{array}{l}\text { Evidence from } \geq 1 \text { properly randomized, } \\
\text { controlled trial }\end{array}$ \\
\hline II & $\begin{array}{l}\text { Evidence from } \geq 1 \text { well-designed clinical trial, } \\
\text { without randomization; from cohort or case- } \\
\text { controlled analytic studies (preferably from } \\
>1 \text { center); from multiple time series; or } \\
\text { from dramatic results from uncontrolled } \\
\text { experiments }\end{array}$ \\
\hline III & $\begin{array}{l}\text { Evidence from opinions of respected } \\
\text { authorities, based on clinical experience, } \\
\text { descriptive studies, or reports of expert } \\
\text { committees }\end{array}$ \\
\hline
\end{tabular}

Ranking Recommendations in Clinical Guidelines was used (Table 1). The final text has been reviewed and approved by all authors.

\section{Pathology and molecular biology}

The correct identification of different EOC histologic subtypes [2] is becoming more challenging and of the foremost importance because of its increasing prognostic, therapeutic implications, and increasingly distinct clinical trials. Together with morphology, the widespread use of immunohistochemistry with WT1, p53, NAPSIN A, beta catenin, and progesterone receptor can help refine up to $95 \%$ of cases and increase the interobserver agreement [III, A] [3]. This information and its molecular counterpart are useful tools (Table 2).

Low-grade serous carcinoma (LGSC) can be differentiated from high-grade serous carcinoma (HGSC) using morphology and p53, and implementing the binary system has been introduced into the new WHO classification. Together with $\mathrm{p} 53$ positivity, sometimes, endometrioid histology is classified as HGSC thus amenable to be treated with PARP inhibitors. The new classification further refines borderline histology and the use of SEE-FIM protocol in ovarian cancer can be used to distinguish its origin [4].

\section{Surgical treatment}

Surgery is a mainstay in staging and treatment of OC. Primary surgery must be performed by gynaecologic oncologist surgeons [II, A].

\section{Early disease (clinical stage I-II)}

At diagnosis, 15-20\% of woman have FIGO stage I disease. Surgery staging in these patients provides prognostic information and influences advice regarding adjuvant

Table 2 Most characteristic IHC staining and relevant molecular features in epithelial ovarian cancer

\begin{tabular}{|c|c|c|c|c|c|c|c|c|c|c|c|}
\hline & \multicolumn{4}{|l|}{ IHC } & \multicolumn{7}{|c|}{ Molecular features } \\
\hline & Abnormal p53 & WT1 & NAPSIN A & PR & $\begin{array}{l}\text { gBRCA } 1 / 2 \\
(\%)\end{array}$ & $\begin{array}{l}\text { PI3KCA } \\
(\%)\end{array}$ & $\begin{array}{l}\text { HER2 } \\
(\%)\end{array}$ & $\begin{array}{l}\text { KRAS } \\
(\%)\end{array}$ & $\begin{array}{l}\text { BRAF } \\
(\%)\end{array}$ & $\begin{array}{l}\text { P53 mut. } \\
(\%)\end{array}$ & $\begin{array}{l}\text { ARID1A } \\
\text { mut. (\%) }\end{array}$ \\
\hline HGSC & + & + & - & + & 20 & & & & & 96 & \\
\hline EC & - & $-1+$ & $-1+$ & + & 8 & & & & & & 30 \\
\hline $\mathrm{CCC}$ & - & - & + & $-1+$ & 6 & 33 & 14 & 14 & & & 46 \\
\hline LGSC & - & + & - & + & $<10$ & & 8 & 41 & 6 & & \\
\hline MC & - & - & - & - & 0 & 5 & 14 & 65 & & & \\
\hline
\end{tabular}

HGSC High-grade serous carcinoma, EC endometrioid carcinoma, $C C C$ clear cell carcinoma, $L G S C$ Low-grade serous carcinoma, $M C$ mucinous carcinoma, Abnormal p53 stands for $<1$ and $>70 \%$ staining, WT1 Wilms Tumour $1, P R$ Progesterone Receptor, $g B R C A 1 / 2$ germline deleterious mutations, HER2 amplification, p53 mut. for mutation 
chemotherapy (CT). Surgical staging for OC originally required an exploratory laparotomy to perform the various procedures recommended by FIGO: peritoneal washings, bilateral salpingo-oophorectomy, hysterectomy, multiple peritoneal biopsies, at least infracolic omentectomy, appendectomy in case of mucinous histology, and pelvic and para-aortic lymph node dissection up to the renal veins [5] [II, A].

Laparotomy has been the standard procedure for surgical staging in OC; however, several retrospective series and meta-analysis establish that laparoscopic approach in the early stages has comparable results to laparotomy in terms of the surgical outcomes and oncological safety $[6,7]$ and could be adequate and feasible for the treatment of early stage OC [II, A].

Lymphadenectomy is recommended in the early stage OC in non-mucinous histological subtypes, as it allows complete staging that provides prognostic information and is associated with greater OS [8] [II, A].

When young women are affected, fertility sparing surgery could be considered in the early stage disease. Patient should be clearly informed about the possible risk of recurrent OC. Patients with stage I with unilateral ovarian involvement and favorable histology (grade 1 or 2 mucinous, serous, endometrioid, or mixed histology) would be amenable to organ preserving surgery but only in combination with complete surgical staging. After fulfilling their wishes of fertility, salpingo-oophorectomy is recommended [III, B].

\section{Advanced disease (clinical stage III-IV)}

In advanced stages, the surgical approach must be an open laparotomy to determine the real extent of the disease, define the stage according to the new FIGO classification (Table 3), and establish surgical techniques to perform. Cytoreduction is associated with increased survival. The volume of residual disease remaining after cytoreductive surgery correlates inversely with survival. Moreover, the main objective of this initial surgery is to obtain an optimal cytoreduction, defined [9] "as the absence of macroscopic residual disease" [II, A]. To achieve this, more complex surgical techniques may be necessary in upper abdomen.

Table 3 FIGO classification 2014

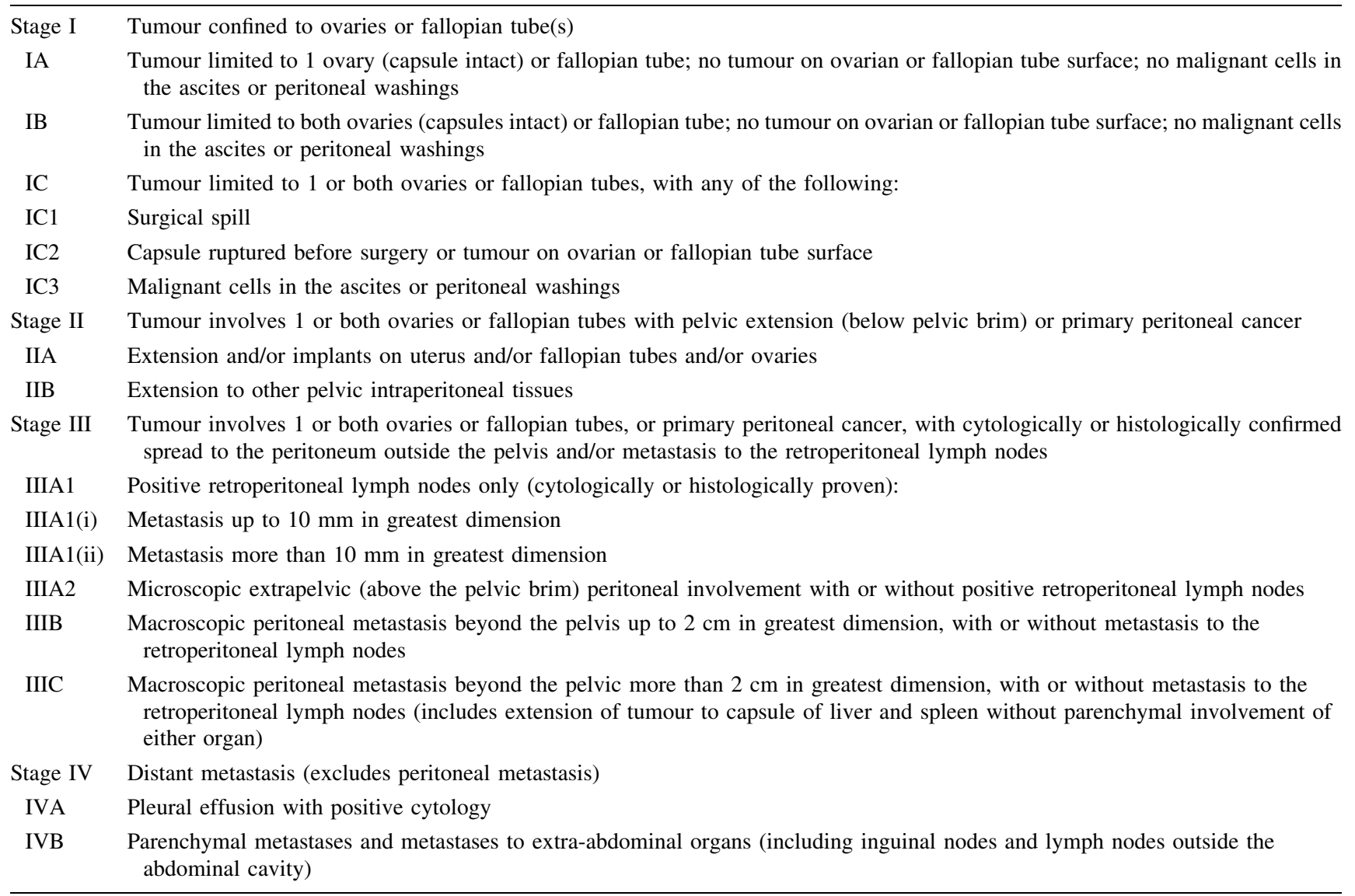

Prat J. International Journal of Gynecology and Obstetrics 2014; 124: 1-5 
The value of pelvic and para-aortic lymphadenectomy in advanced stages still needs to be confirmed prospectively in an undergoing phase III trial and current data are based on an improvement in OS in a combined analysis of three randomized trials conducted by the AGO-OVAR group [10]. Therefore, a pelvic and para-aortic lymphadenectomy is recommended [II, A].

Contraindications for this upfront maximal debulking surgery have been defined as: poor performance status, mesentery root involvement, extra-abdominal visceral disease, multiple intraparenchymal liver metastases, or intestinal massive-serosal carcinomatosis. [II, A].

\section{Recurrent disease}

The benefit of secondary cytoreductive surgery is unclear. The DESKTOP I trial found that surgery with no residual disease was associated with improved survival and identified good performance status [11], no residual tumour after first surgery, and absence of ascites, as predictive factors for complete resection. In the DESKTOP II trial, the predictive value of these factors was validated in patients with disease-free interval $\geq 6$ months and DESKTOP III is currently evaluating it prospectively.

Therefore, surgery at relapse is not a standard treatment, but could be considered in patients with DFI $>6$ months, no residual disease after first surgery, good PS, and absence of ascites [II, B].

The use of HIPEC (Hyperthermic Intraperitoneal Chemotherapy) in OC relapses following surgical cytoreduction has no role in OC. There is no evidence from prospective randomized studies and the published studies are very heterogeneous and a pooled analysis has not shown any advantage [12]. HIPEC should not be recommended as treatment after secondary cytoreductive surgery in $\mathrm{OC}$ relapse.

\section{Neoadjuvant chemotherapy}

Two phase III randomized studies have reported results in this setting. The EORTC-55971 and the CHORUS trial showed that in women with stage IIIC or IV OC, primary debulking surgery followed by at least six cycles of platinum-based CT or three cycles of platinum-based neoadjuvant CT (NAC), followed by interval debulking surgery, and then at least three more cycles of platinum-based CT, achieved the same OS [13, 14]. However, some concerns have arisen regarding the quality of the surgery performed and the use of NAC in candidates for optimal upfront debulking surgery. Only the subset of patients with upfront surgery and no residual disease seemed to achieve higher survival rates in a subgroup analysis.

NAC should be reserved for those patients who cannot tolerate PDS and/or for whom optimal cytoreduction is not feasible after an adequate evaluation performed by an expert surgical team [I, B]. Otherwise, PDS followed by adjuvant platinum and taxane combination is the recommended standard treatment $[\mathrm{I}, \mathrm{A}]$.

\section{Initial systemic therapy}

\section{Early stages}

Adjuvant platinum-based CT after surgery is indicated in high-risk early stages (IA and IB Grade 3, clear cell tumours, and any grade of stages IC and IIA) [15] [I, A]. Only low-risk patients (stages IA/B Grade I) with complete and comprehensive surgical staging require observation exclusively. The recommended regimen consists of at least three cycles of paclitaxel-carboplatin [I, A], although six cycles should be recommended in high-grade serous histology [II, B].

\section{Advanced stages}

Different options of first-line CT are available for advanced stage (III-IV) OC patients: conventional CT, dose-dense, intraperitoneal, or conventional CT combined with antiangiogenics. In Table 4, the different strategies in this setting are summarized.

\section{Conventional chemotherapy}

Standard post-operative treatment in advanced stages after complete surgical staging consists of a combination of carboplatin (AUC 5-6) and paclitaxel $\left(175 \mathrm{mg} / \mathrm{m}^{2}\right)$ every 3 weeks for 6 cycles [I,A]. Alternative CT regimens, intraperitoneal regimens, or the addition of bevacizumab will be discussed below. For patients not eligible to receive a taxane (specifically paclitaxel), the combination of carboplatin and pegylated liposomal doxorubicin (PLD) is recommended [16] [I, B].

\section{Dose-dense therapy}

A dose-dense regimen was superior to 3-weekly carboplatin plus paclitaxel in a large, randomized Japanese trial (JGOG 3062), with increased PFS and OS, but worse toxicity profile, mainly hematological and neuropathy [17]. However, the results of the MITO 7 trial that compared a 
Table 4 Systemic therapy options after upfront surgery or interval debulking surgery (preferred options are selected based on evidence)

\begin{tabular}{llll}
\hline & $\begin{array}{l}\text { IV chemotherapy without } \\
\text { bevacizumab }\end{array}$ & $\begin{array}{l}\text { IV chemotherapy with } \\
\text { bevacizumab }\end{array}$ & IP chemotherapy \\
\hline Upfront surgery & & Preferred option & Not indicated \\
Stage III with RD $\geq 1 \mathrm{~cm}$ Stage IV & Option & Option & Preferred option* \\
Stage III with RD $<1 \mathrm{~cm}$ & Option & Option & Preferred option* \\
Stage III without RD & Option & Option & Not indicated \\
Interval debulking surgery & & Option & Option \\
Stage III with RD $\geq 1 \mathrm{~cm}$ Stage IV & Option & Option & Option \\
Stage III with RD $<1 \mathrm{~cm}$ & Option & & \\
Stage III without RD & Option & &
\end{tabular}

* In fit patients

weekly paclitaxel and carboplatin schedule with 3-weekly carboplatin and paclitaxel, and the GOG 262 trial that compared, the weekly paclitaxel and carboplatin schedule with the 3-weekly schedule regardless of bevacizumab exposure have not confirmed the benefit of the dose-dense regimens in Caucasian population. For this reason, dosedense therapy cannot be considered the standard of care in first-line setting [I, B].

\section{Intraperitoneal chemotherapy}

Three large randomized studies (GOG 104, GOG 114, and GOG 172) and one meta-analysis have found clinically significant improvements in PFS and OS when part of the CT is administered directly in the peritoneal cavity after upfront surgery. GOG 172 showed an improvement of median OS from 49.5 to 66.9 months, favorable to the IP CT arm, but with a significant toxicity [18]. A recent update of GOG 114 and GOG 172 studies concluded that OS advantage of intraperitoneal (IP) CT extends beyond 10 years and improves with increasing number of IP cycles [19]. GEICO group published an outpatient modified intraperitoneal regimen that resulted in a lesser toxicity and a greater rate of treatment completion than previously reported [20].

To conclude, IP CT is shown to be superior to IV CT after primary debulking surgery and is another standard option in the management of selected patients with stage III with optimal surgery or residual tumour $\leq 1 \mathrm{~cm}[\mathrm{I}, \mathrm{A}]$. The role of IP CT after interval debulking surgery is controversial, although it could be an option for some patients [I, B].

\section{Antiangiogenic therapy}

Phase III data are currently available in front-line therapy on Bevacizumab, Pazopanib, and Nintedanib.

Two large randomized studies (GOG 218 and ICON 7) have reported that bevacizumab added to the initial CT followed by maintenance period with bevacizumab improves PFS in comparison with standard CT alone in patients with FIGO III and IV OC. The improvement in PFS was 3.8 months $(\mathrm{HR}=0.72)$ in GOG trial and 1.5 months $(\mathrm{HR}=0.81)$ in ICON 7. According to a metaanalysis, the benefit in OS of 4.8 months is observed in patients with either stage III and residual disease $>1 \mathrm{~cm}$, or stage IV disease [21, 22].

Bevacizumab added to the initial CT followed by a maintenance period of bevacizumab should be included for patients who, following standard surgery, have macroscopic residual disease [I, A].

Pazopanib and Nintedanib are not approved for OC treatment.

\section{Treatment of recurrent disease}

\section{Factors to consider when selecting therapy in recurrent ovarian carcinoma}

Approximately, 50-90\% of patients with advanced OC will have a relapse in the first 5 years after the diagnosis depending on the initial FIGO stage at presentation, use of neoadjuvant CT, and residual disease after upfront cytoreductive surgery. Treatment of patients with recurrent disease is a great challenge due to the heterogeneity of disease and clinical situations. We need to consider many different factors for selecting the different therapy of the relapse (Table 5).

Factors depending on the tumour

- The site of disease and extension to consider surgical options.

- Histological subtype.

- BRCA1/2 status to identify candidates to olaparib.

Factors depending on the patient

- Treatment-free interval: Platinum-free interval (TFIp) has been considered classically a predictive factor of 
response to platinum-rechallenge. Patients have been divided in platinum-resistant, partially platinum-sensitive, and platinum-sensitive according to the TFIp (less than 6, 6-12, or $>12$ months).

- Type of previous therapy: It should be considered the previous use of cytotoxic agents and response obtained, as well as the previous use of targeted agents like antiangiogenic therapy or PARP inhibitors.

- Residual toxicity after the previous lines.

- Co-morbidities of the patient and special geriatric population.

- Preference and expectations of the patient.

\section{Relapse with platinum-free interval $>6$ months}

A platinum-based combination is associated with a longer PFS and OS in comparison to single-agent platinum. There is no combination that can be considered superior in terms of efficacy; the schedule selection should be based on the toxicity profile [18].

A randomized phase III trial of bevacizumab combined with carboplatin-gemcitabine, in patients in first relapse who have not been treated with antiangiogenic therapy, has shown a benefit in RR and PFS [23]. The combination of bevacizumab with carboplatin and paclitaxel in this setting has also shown improvement in PFS [24].

In patients with HGSC OC platinum-sensitive relapse and $B R C A 1 / 2$ mutation who respond to platinum, the maintenance treatment with olaparib improves PFS with a HR of 0.18 and an increment in median PFS from 4.3 to 11.2 months, but the trial was underpowered for OS [25].

Patients with TFIp of 6-12 months have lower response rates to platinum and different strategies beyond carboplatin-based regimens are under investigation. A subgroup analysis of a randomized trial comparing trabectedin and pegylated liposomal doxorubicin (PLD) with PLD showed that those patients with TFIp of 6-12 months treated with the non-platinum combination and a platinum-based therapy at progression obtained a benefit in OS [26]. However, a randomized clinical trial has shown that the use of nonplatinum single agent followed by platinum in patients with relapsed ovarian cancer and a PFI of 6-12 months was inferior to platinum-based combination [27].

In patients with TFIp $>6$ months, the standard treatment is a platinum combination $[\mathrm{I}, \mathrm{A}]$, with the consideration of adding bevacizumab in first relapse if the patients have not been treated with bevacizumab in first line [I, A]. In BRCA-mutated patients who respond to platinum, maintenance with olaparib must be considered [IA]. In patients with TFIp 6-12 months, a platinum combination [I, A] or trabectedin-PLD (I, B) could be considered.

\section{Relapse with platinum-free interval $<6$ months}

Patients with TFIp $<6$ months have poor prognosis. There is no I level evidence of active treatment versus best supportive care in this clinical setting. Yet, it is known that patients progressing on two consecutive lines of treatment should be considered for best supportive care or clinical trials depending on their performance status [18].

These patients should be treated with sequential single-agent CT to improve symptom control and quality of life. Palliative chemotherapies accepted are PLD, weekly paclitaxel, topotecan, and gemcitabine [18]. They have shown activity in several phase III trials with response rates of less than 20\%, a median PFS of 3-4 months, and a median OS of 9-12 months. None of them has proven to be superior in terms of RR, PFS, and OS. Clinician must choose wisely based on the above-mentioned criteria.

Table 5 Treatment options in relapsed ovarian cancer

\begin{tabular}{|c|c|c|}
\hline \multicolumn{2}{|l|}{ TFIp $>6$ months } & \multirow[t]{2}{*}{ TFIp $<6$ months } \\
\hline BRCA-mutated & Non-BRCA-mutated & \\
\hline \multicolumn{3}{|l|}{ Non-previous bevacizumab } \\
\hline $\begin{array}{l}\text { Platinum combination and maintenance with } \\
\text { olaparib (IA) }\end{array}$ & $\begin{array}{l}\text { Carbo-gem and } \\
\text { bevacizumab (IA) }\end{array}$ & $\begin{array}{l}\text { Single-agent (weekly paclitaxel, PLD or topotecan) }+ \\
\text { bevacizumab (IA) }\end{array}$ \\
\hline Carbo-gem and bevacizumab (IA) & Platinum combination (IA) & Single-agent (weekly paclitaxel, PLD or topotecan, \\
\hline Platinum combination (IA) & PLD + trabectedin* $(\mathrm{IB})$ & gemcitabine) (IA) \\
\hline \multicolumn{3}{|l|}{ PLD + trabectedin* $(\mathrm{IB})$} \\
\hline \multicolumn{3}{|l|}{ Previous bevacizumab } \\
\hline $\begin{array}{l}\text { Platinum combination and maintenance with } \\
\text { olaparib (IA) }\end{array}$ & $\begin{array}{l}\text { Platinum combination (IA) } \\
\text { PLD + trabectedin* (IB) }\end{array}$ & $\begin{array}{l}\text { Single-agent (weekly paclitaxel, PLD or topotecan, and } \\
\text { gemcitabine) (IA) }\end{array}$ \\
\hline \multicolumn{3}{|l|}{ Platinum combination (IA) } \\
\hline PLD + trabectedin* $(\mathrm{IB})$ & & \\
\hline
\end{tabular}

* If platinum is not an option 
For platinum-resistant patients who have not received neither more than two previous lines nor prior bevacizumab, the addition of the latter to weekly paclitaxel, PLD, or topotecan has shown to improve PFS (3.4-6.7 months) and OS (13.3 vs 16.7 months) [28]. This combination therapy also significantly improved symptoms with a significantly higher proportion of patients achieving the predefined $15 \%$ improvement in abdominal/GI symptoms.

In platinum-resistant $\mathrm{OC}$ patients, single-drug therapy or a combination with bevacizumab in case they have not received this drug previously is recommended [I, A].

\section{Compliance with ethical standards}

Conflict of interest The authors declare that they have no conflict of interest relating to the publication of this manuscript.

Open Access This article is distributed under the terms of the Creative Commons Attribution 4.0 International License (http://crea tivecommons.org/licenses/by/4.0/), which permits unrestricted use, distribution, and reproduction in any medium, provided you give appropriate credit to the original author(s) and the source, provide a link to the Creative Commons license, and indicate if changes were made.

\section{References}

1. Bowtell DD, Bohm S, Ahmed AA, Aspuria PJ, Bast RC Jr, Beral V, et al. Rethinking ovarian cancer II: reducing mortality from high-grade serous ovarian cancer. Nat Rev Cancer. 2015;5(11):668-79 (PubMed PMID: 26493647. Pubmed Central PMCID: 4892184).

2. Kurman RJ, Carcangiu ML, Herrington CS, Young RH. WHO classification of tumors of the female reproductive organs. 4th ed, vol 6. WHO Press; 2014.

3. Kobel M, Rahimi K, Rambau PF, Naugler C, Le Page C, Meunier L, et al. An immunohistochemical algorithm for ovarian carcinoma typing. Int J Gynecol Pathol. 2016;35(5):430-41 (PubMed PMID: 26974996. Pubmed Central PMCID: 4978603).

4. Singh N, Gilks CB, Hirschowitz L, Kehoe S, McNeish IA, Miller D, et al. Primary site assignment in tubo-ovarian high-grade serous carcinoma: consensus statement on unifying practice worldwide. Gynecol Oncol. 2016;141(2):195-8 (PubMed PMID: 26827965)

5. Trimbos B, Timmers P, Pecorelli S, Coens C, Ven K, van der Burg M, et al. Surgical staging and treatment of early ovarian cancer: long-term analysis from a randomized trial. J Ntl Cancer Inst. 2010;102(13):982-7 (PubMed PMID: 20445161. Pubmed Central PMCID: 2911043).

6. Koo YJ, Kim JE, Kim YH, Hahn HS, Lee IH, Kim TJ, et al. Comparison of laparoscopy and laparotomy for the management of early-stage ovarian cancer: surgical and oncological outcomes. J Gynecol Oncol. 2014;25(2):111-7 (PubMed PMID: 24761214. Pubmed Central PMCID: 3996260).

7. Bellia A, Vitale SG, Lagana AS, Cannone F, Houvenaeghel G, Rua S, et al. Feasibility and surgical outcomes of conventional and robot-assisted laparoscopy for early-stage ovarian cancer: a retrospective, multicenter analysis. Arch Gynecol Obstet. 2016;294(3):615-22 (PubMed PMID: 27040423).

8. Zhou J, Shan G, Chen Y. The effect of lymphadenectomy on survival and recurrence in patients with ovarian cancer: a systematic review and metaanalysis. Jpn J Clin Oncol. 2016;46(8):718-26 (PubMed PMID: 27272175).

9. Stuart GC, Kitchener H, Bacon M, du Bois A, Friedlander M, Ledermann J, et al. Gynecologic Cancer InterGroup (GCIG) consensus statement on clinical trials in ovarian cancer: report from the Fourth Ovarian Cancer Consensus Conference. Int J Gynecol Cancer. 2010;21(4):750-5 (PubMed PMID: 21543936).

10. du Bois A, Reuss A, Harter P, Pujade-Lauraine E, Ray-Coquard I, Pfisterer J, et al. Potential role of lymphadenectomy in advanced ovarian cancer: a combined exploratory analysis of three prospectively randomized phase III multicenter trials. J Clin Oncol. 2010;28(10):1733-9 (PubMed PMID: 20194855).

11. Harter P, Hahmann M, Lueck HJ, Poelcher M, Wimberger P, Ortmann O, et al. Surgery for recurrent ovarian cancer: role of peritoneal carcinomatosis: exploratory analysis of the DESKTOP I Trial about risk factors, surgical implications, and prognostic value of peritoneal carcinomatosis. Ann Surg Oncol. 2009;16(5):1324-30 (PubMed PMID: 19225844).

12. Chiva LM, Gonzalez-Martin A. A critical appraisal of hyperthermic intraperitoneal chemotherapy (HIPEC) in the treatment of advanced and recurrent ovarian cancer. Gynecol Oncol. 2015;136(1):130-5.

13. Vergote I, Trope CG, Amant F, Kristensen GB, Ehlen T, Johnson N, et al. Neoadjuvant chemotherapy or primary surgery in stage IIIC or IV ovarian cancer. N Engl J Med. 2010;363(10):943-53 (PubMed PMID: 20818904).

14. Kehoe S, Hook J, Nankivell M, Jayson GC, Kitchener H, Lopes T, et al. Primary chemotherapy versus primary surgery for newly diagnosed advanced ovarian cancer (CHORUS): an open-label, randomised, controlled, non-inferiority trial. Lancet. 2015;386(9990):249-57 (PubMed PMID: 26002111).

15. Trimbos JB, Parmar M, Vergote I, Guthrie D, Bolis G, Colombo N, et al International Collaborative Ovarian Neoplasm trial 1 and Adjuvant ChemoTherapy In Ovarian Neoplasm trial: two parallel randomized phase III trials of adjuvant chemotherapy in patients with early-stage ovarian carcinoma. J Natl Cancer Inst. 2003;95(2):105-12 (PubMed PMID: 12529343).

16. Pignata S, Scambia G, Ferrandina G, Savarese A, Sorio R, Breda E, et al. Carboplatin plus paclitaxel versus carboplatin plus pegylated liposomal doxorubicin as first-line treatment for patients with ovarian cancer: the MITO-2 randomized phase III trial. J Clin Oncol. 2011;29(27):3628-35 (d PubMed PMID: 21844495).

17. Katsumata N, Yasuda M, Isonishi S, Takahashi F, Michimae H, Kimura E, et al. Long-term results of dose-dense paclitaxel and carboplatin versus conventional paclitaxel and carboplatin for treatment of advanced epithelial ovarian, fallopian tube, or primary peritoneal cancer (JGOG 3016): a randomised, controlled, open-label trial. Lancet Oncol. 2013;14(10):1020-6 PubMed PMID: 23948349

18. Gonzalez-Martin A, Bover I, Del Campo JM, Redondo A, Vidal L. Spanish Society for Medical Oncology. SEOM guideline in ovarian cancer 2014. Clin Transl Oncol. 2014;16(12):1067-71 (PubMed PMID: 25351169. Pubmed Central PMCID: 4239783).

19. Tewari D, Java JJ, Salani R, Armstrong DK, Markman M, Herzog T, et al. Long-term survival advantage and prognostic factors associated with intraperitoneal chemotherapy treatment in advanced ovarian cancer: a gynecologic oncology group study. J Clin Oncol. 2015;33(13):1460-6 (PubMed PMID: 25800756. Pubmed Central PMCID: 4404424)

20. Oaknin A, Roda D, Gonzalez-Martin A, Chiva L, Garcia-Donas J, de Juan A, et al. Feasibility of a modified outpatient regimen of intravenous/intraperitoneal chemotherapy in optimally debulked stage III ovarian cancer patients: a GEICO study. Int J Gynecol Cancer. 2011;21(6):1048-55 PubMed PMID: 21738038.

21. Aravantinos G, Pectasides D. Bevacizumab in combination with chemotherapy for the treatment of advanced ovarian cancer: a systematic review. J Ovar Res. 2014;7:57 (PubMed PMID: 24864163. Pubmed Central PMCID: 4033616).

22. Oza AM, Cook AD, Pfisterer J, Embleton A, Ledermann JA, Pujade-Lauraine E, et al. Standard chemotherapy with or without bevacizumab for women with newly diagnosed ovarian cancer (ICON-7): overall survival results of a phase 3 randomsed trial. Lancet oncol. 2015;16:928-36.

23. Aghajanian C, Blank SV, Goff BA, Judson PL, Teneriello MG, Husain A, et al. OCEANS: a randomized, double-blind, placebo-controlled phase III trial of chemotherapy with or without bevacizumab in patients with platinum-sensitive recurrent epithelial ovarian, primary peritoneal, or fallopian tube cancer. J Clin Oncol. 2012;30(17):2039-45 (PubMed PMID: 22529265. Pubmed Central PMCID: 3646321).

24. Colemana RL, Bradya MF, Herzogc TJ, Sabbatinid P, Armstronge DK, Walker $\mathrm{JL}$, et al. A phase III randomized controlled clinical trial of carboplatin and paclitaxel alone or in combination with bevacizumab followed by bevacizumab and secondary cytoreductive surgery in platinum-sensitive, recurrent ovarian, peritoneal primary and fallopian tube cancer. Presented at: Society of Gynecologic Oncology's Annual Meeting on Women's Cancer 2015; March 28-31, 2015; Chicago, IL. Abstract 3 (late breaking).

25. Ledermann J, Harter P, Gourley C, Friedlander M, Vergote I, Rustin G, et al. Olaparib maintenance therapy in patients with platinum-sensitive relapsed serous ovarian cancer: a preplanned retrospective analysis of outcomes by BRCA status in a randomised phase 2 trial. Lancet Oncol. 2014;15(8):852-61 PubMed PMID: 24882434.

26. Poveda A, Vergote I, Tjulandin S, Kong B, Roy M, Chan S, et al. Trabectedin plus pegylated liposomal doxorubicin in relapsed ovarian cancer: outcomes in the partially platinum-sensitive (platinum-free interval 6-12 months) subpopulation of OVA-301 phase III randomized trial. Ann Oncol. 2011;22(1):39-48 (PubMed PMID: 20643862. Pubmed Central PMCID: 3003616).

27. Pignata S, Scambia G, Raspagliesi F, Murgia V, Pisano C, Salutari V, et al. The MITO8 phase III international multicenter randomized study testing the effect on survival of prolonging platinum-free interval (PFI) in patients with ovarian cancer (OC) recurring between 6 and 12 months after previous platinum-based chemotherapy: A collaboration of MITO, MANGO, AGO, BGOG, ENGOT, and GCIG. J Clin Oncol. 2016;34(suppl; abstr 5505).

28. Pujade-Lauraine E, Hilpert F, Weber B, Reuss A, Poveda A, Kristensen G, et al. Bevacizumab combined with chemotherapy for platinum-resistant recurrent ovarian cancer: the AURELIA open-label randomized phase III trial. J Clin Oncol. 2014;32(13):1302-8 (PubMed PMID: 24637997). 